\title{
Should recommendations be made to reduce dietary sodium intake? The case against recommendations
}

\section{By A. F. Lever, MRC Blood Pressure Unit, Western Infirmary, Glasgow GII 6NT}

We are here to consider whether the evidence of benefit from reducing dietary sodium in hypertensive patients or in the population at large is sufficient to justify recommendation to the general public that dietary $\mathrm{Na}$ is reduced. I shall concentrate on four questions. First, and most important, when reduction of dietary $\mathrm{Na}$ lowers blood pressure will the risks associated with high blood pressure be reversed? Clearly it is pointless lowering blood pressure if the risks are not reversed. Indeed, there are circumstances in which it is known that lowering blood pressure in hypertension does not reverse risks associated with high blood pressure. Second, also important, but I believe less relevant to the debate, is dietary $\mathrm{Na}$ involved in the pathogenesis of hypertension? It does not matter $\mathrm{so}$ far as recommendations are concerned if $\mathrm{Na}$ is or is not involved in pathogenesis provided reduction of dietary $\mathrm{Na}$ lowers blood pressure and this reduces the risks associated with high blood pressure. Third, does reduction of dietary $\mathrm{Na}$ within the range one can expect to achieve in a general population lower blood pressure in hypertensive and normal individuals? Fourth, and finally, how feasible is it to reduce dietary $\mathrm{Na}$ ?

It was claimed recently in a review of three prospective randomized control trials (which we shall consider later) that practical Na restriction lowered blood pressure by $8 \mathrm{mmHg}$ and that such a decrease would lower cardiovascular mortality by $10-15 \%$. This optimistic prediction is based on a false premise. It is true that $\mathrm{Na}$ restriction did lower blood pressure by $8 \mathrm{mmHg}$ in these trials, but the patients were hypertensive. The figure of 10-15\% was taken from a different study, not concerned with hypertensive patients, and had no information on the effect of reducing blood pressure. Indeed, there is no evidence in normal or hypertensive subjects that a reduction of this order by any treatment would lower mortality. In particular, I know of no evidence that risk is reduced by dietary $\mathrm{Na}$ deprivation. In our own experience of treatment in hypertensive patients using drugs, a reduction of blood pressure lowered risk but not to the level found in the general population, even when blood pressure was reduced to that of the general population (Isles et al. 1986).

Most of the evidence in favour of recommendations on dietary salt intake comes from epidemiology. A wide range of populations has been studied, from primitive societies with an individual daily intake of $10 \mathrm{mmol} \mathrm{Na}$ to industrial societies with intakes twenty times higher than this. There is without doubt a reasonably good relation between average blood pressure of these populations and their average 
dietary intake of $\mathrm{Na}$. The higher the intake the greater the blood pressure of that population. The problem with many of these studies is methodological: the comparison is based on blood pressure measured by different methods in different parts of the world and, as indicated below, there are other relevant differences in the populations compared (Brown et al. 1984).

The second type of epidemiological evidence is the very important observation that when primitive people migrate from the country to the town, their dietary $\mathrm{Na}$ intake and their blood pressure increase. However, the act of migration involves changes other than increasing dietary Na. Compared with town dwellers, people living in the country have a lower energy intake and are thinner, they eat more vegetables and thus more potassium, they have a higher fibre intake because they eat more vegetables, they have a lower protein intake because they eat less meat and a lower fat intake for the same reason. Each of these has an influence on blood pressure: a low-energy diet in itself can reduce blood pressure in hypertensives, increasing dietary $\mathrm{K}$ can lower blood pressure slightly, a high-fibre intake is said itself to lower blood pressure, a low-protein intake almost certainly lowers blood pressure since if a vegetarian eats meat his blood pressure rises. Reduction of dietary fat may in itself lower blood pressure to a greater extent than reduction of dietary $\mathrm{Na}$. Thus, there is the potential for factors other than dietary $\mathrm{Na}$ to cause a reduction of blood pressure when primitive people migrate from the country to the town (Brown et al. 1984). The same factors compromise the correlation of blood pressure and $\mathrm{Na}$ intake when data from different countries are compared. Thus, I am not entirely persuaded that epidemiological evidence of an association between dietary $\mathrm{Na}$ and blood pressure reflects a causal connection between the two. The evidence is suggestive but cannot be the basis for a recommendation to the public.

I shall now consider evidence for such a link from studies in animals. Dahl (1977) suggested that the response of blood pressure to changing dietary $\mathrm{Na}$ varied markedly in individuals (rats and men) and that part of the reason for the variation was genetic. He was able to breed rats with increased sensitivity in which a large change of dietary $\mathrm{Na}$ produced a large change of blood pressure. There have been many studies in man since showing that some but not all patients with essential hypertension are sensitive to change of dietary $\mathrm{Na}$. The response in normal subjects to the same change of $\mathrm{Na}$ is much less or negligible (see Brown et al. 1984). I should emphasize that these are short-term studies of usually between $3 \mathrm{~d}$ and 2 weeks. This is not the type of information which is needed to support a dietary policy for a large population over a prolonged period.

How specific is the link between dietary $\mathrm{Na}$ and hypertension? If $\mathrm{Na}$ restriction reduces blood pressure are we to assume that increased dietary $\mathrm{Na}$ has raised blood pressure in the first place? If the assumption is correct, the higher dietary $\mathrm{Na}$ intake of Western society is responsible for the greater frequency of hypertension and there would be a good case for prophylactic measures to reduce dietary $\mathrm{Na}$. Unfortunately, the effect of dietary $\mathrm{Na}$ deprivation on blood pressure in hypertensives is very far from specific. Blood pressure can be reduced just as effectively by calcium-channel antagonists, $\beta$-blockers, $\alpha$-blockers, diuretics, 
aldosterone antagonists and inhibitors of angiotensin II converting enzyme. This means that the response seen during Na deprivation is non-specific. No argument can be mounted to the effect that dietary salt is too high because lowering salt reduces blood pressure.

Generally, the higher blood pressure is before treatment the greater the fall during treatment. This applies to treatment by $\mathrm{Na}$ restriction or by drugs (see Brown et al. 1984). Too much has been read into this observation in my view. It is no more surprising than the correlation found between the height of an aeroplane and the distance fallen by a parachutist jumping from that plane. It has practical implications. There is some dispute about whether blood pressure is reduced at all when dietary $\mathrm{Na}$ is decreased. The controversy centres on studies of patients at the lower end of the range of blood pressure. If hypertension is mild it is to be expected that the fall of blood pressure will be small and that different studies will appear to give different results. Generally, the confidence intervals of these studies are large and a genuine discrepancy has not been established. The studies by Parijs et al. (1973), Morgan et al. (1978) and MacGregor et al. (1982) are perhaps the best of those concerned with moderate hypertension. They show a significant reduction of about $7 \mathrm{mmHg}$ on average. Thus, while a reduction of dietary $\mathrm{Na}$ does lower blood pressure in mild to moderate hypertensives, it does not follow that this is the best form of therapy or that when effective it will also reverse mortality associated with high blood pressure. There is little or no information on the effect of dietary $\mathrm{Na}$ depletion on blood pressure in normal subjects. It is important that this information is obtained since in three studies of the normal rat, dietary $\mathrm{Na}$ deprivation actually raised blood pressure (Munoz-Ramirez et al. 1980; Seymour et al. 1980; Webb et al. 1986).

In our own study (Webb et al. 1986), mortality was increased significantly by a minor surgical procedure in Na-deprived animals. A Swedish study showed that Na-deprived rats subjected to haemorrhage are more likely to develop irreversible shock (Gotheberg et al. 1983). Are these adverse effects in the rat relevant to normal man? At a recent debate on this subject at the Royal College of Physicians there were several who claimed that observations in the rat are irrelevant to a policy in man. My view is that in the absence of evidence in man, it would be unwise to reject any evidence in the rat. Who is to say until the study is done in man whether a decrease of dietary $\mathrm{Na}$ has good, bad or neutral effects on mortality and morbidity in the normal population?

In conclusion, there are two separate questions. (I) Should dietary $\mathrm{Na}$ be reduced as part of the treatment for mild hypertension? I agree that blood pressure is reduced by Na deprivation, but we do not know whether it falls more or less than with drugs or whether its effect on mortality and morbidity differs from the effect of drugs. Comparative studies are needed. (2) Should recommendations be made to the general public on a reduction of dietary Na? In the USA the Select Committee on Nutrition and Human Needs, United States Senate (1977) has already made such recommendations. The issue here is more important, but even less certain. In our view (Brown et al. 1984), low-Na diets are not demonstrably 
good or demonstrably bad. The case for and against recommendation is untested and based on circumstantial evidence. If recommendations are to be made, tests should be done.

\section{REFERENCES}

Brown, J. J., Lever, A. F., Robertson, J. I. S. \& Semple, P. F. (1984). Quarterly fournal of Medicine 212, 427-437.

Dahl, L. K. (1 977). In Hypertension, Pathophysiology and Treatment, pp. 548-559 [J. Genest, E. Koiw and O. Kuchel, editors]. New York: McGraw-Hill Book Co.

Gotheberg, G., Lundin, S., Aurell, M. \& Folkow, B. (1983). Fournal of Hypertension 1, Suppl. 2, $24-26$.

Isles, C. G., Walker, L. M., Beevers, G. D., Brown, I., Cameron, H. L., Clark J., Hawthorne, V., Hole, D., Lever, A. F., Robertson, J. W. K. \& Wapshaw, J. A. (Ig86). Fournal of Hypertension (In the Press).

MacGregor, G. A., Best, F. E. \& Cam, J. M. (1982). Lancet i, 351-355.

Morgan, T., Adam, W., Gillies, A., Wilson, M., Morgan, G. \& Carney, S. (1978). Lancet i, $227-230$.

Munoz-Ramirez, H., Chatelain, R. E., Bumpus, F. M. \& Khairallah, P. A. (1980). American fournal of Physiology 238, H889-H894.

Parijs, J., Joossens, J. V., Van der Linden, L., Verstreken, G. \& Amery, A. K. P. C. (1973). American Heart Yournal 85, 22-34.

Select Committee on Nutrition and Human Needs, United States Senate (1977). Dietary Goals for the United States, pp. 49-52 [G. McGovern, chairman]. Washington DC: Government Printing Office.

Seymour, A. A., Davis, J. O., Freeman, R. H., DeForrest, J. M., Rowe, B. P., Stephens, G. A. \& Williams, G. M. (1980). Hypertension 2, $125-129$.

Webl, D. J., Clark, S., Brown, W. \& Lever, A. F. (1986). Fournal of Hypertension (In the Press). 